\title{
Natural Antioxidant Extracted Waste Cooking Oil as Sustainable Biolubricant Formulation in Tribological and Rheological Applications
}

\author{
Nisha Singh ${ }^{1} \cdot$ Priyanka Agarwal $^{1} \cdot$ Suheel K. Porwal ${ }^{1}$ (1)
}

Received: 29 October 2021 / Accepted: 21 February 2022 / Published online: 1 March 2022

(c) The Author(s), under exclusive licence to Springer Nature B.V. 2022

\begin{abstract}
Developing eco-friendly formulations using waste cooking oil as renewable biomass is of great interest and commercial importance in the fuels and lubricant industry. This manuscript reports novel study on preparing a biolubricant formulations as WCO-1, WCO-2 and WCO-3 by blending the curcumin extracted soybean waste cooking oil in three different compositions viz $10 \%, 20 \%, 30 \% \mathrm{v} / \mathrm{v}$ with the mineral base oil $\mathrm{N}-150$. Curcumin was extracted as a natural antioxidant in $0.5 \mathrm{wt} \%$ waste cooking oil to inhibit thermal oxidation. This study comprises a detailed analysis in terms of tribological, rheological and thermophysical characteristics such as viscosity, viscosity index, pour point and flash point parameters of the biolubricant by standard ASTM methods. Further, tribological and rheological analysis was done by the four-ball wear tester and Anton Paar, MCR-72, respectively. The thermophysical evaluation of WCO formulated biolubricant has shown excellent properties. The viscosity index of the formulated biolubricant increases with an increase in the concentration of waste cooking oil. In contrast, the pour point has also been depressing at lower temperature conditions. Thus, WCO based biolubricant was found to be more effective at extreme temperature conditions than the mineral base oil ( $\mathrm{N}-150)$. Rheological studies have indicated the non-Newtonian behaviour of the biolubricant with an increase in shear rate. Whereas, tribological analysis demonstrates that wear scar diameter has significantly reduced from 0.685 to $0.573 \mathrm{~mm}$, and the coefficient of friction decreased from 0.117 to 0.080 with respect to the mineral base oil. Thus, a straightforward green approach has been discovered by directly utilizing waste cooking oil for biolubricant formulation.
\end{abstract}

\section{Graphical abstract}

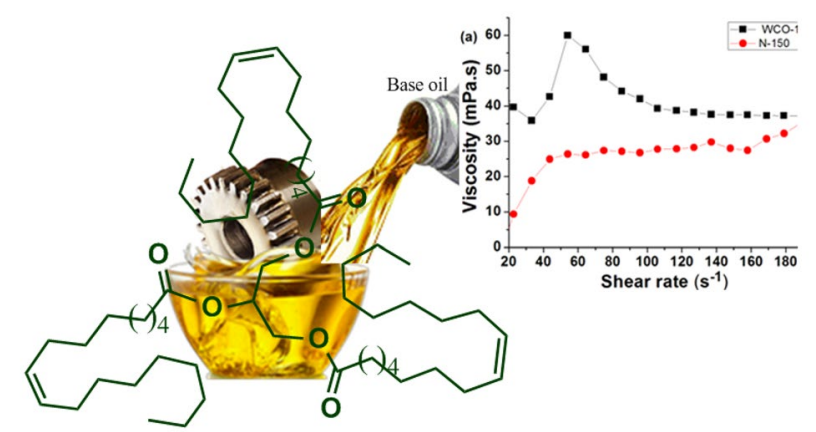

Biolubricant formulation from curcumin extracted waste cooking oil

Keywords Biolubricant $\cdot$ Flash point $\cdot$ Pour point $\cdot$ Viscosity index $\cdot$ Coefficient of friction $\cdot$ Wear scar diameter $\cdot$ Rheology

Suheel K. Porwal

skpchemistry@gmail.com

1 Analytical Chemistry Lab, Department of Chemistry, DIT University, Dehradun, Uttarakhand 248009, India

\section{Statement of Novelty}

This study targets the valorization of waste cooking oil for biolubricant formulation. The vast amount of work reported is based upon chemical modification of waste cooking oil, 
whereas in this study, it is utilized directly without chemical modification to formulate biolubricant. Natural antioxidant curcumin was added to improve the oxidative stability of the waste cooking oil. The cost of the prepared biolubricant is significantly reduced as compared to the mineral base oil.

\section{Introduction}

Petroleum origin lubricants are certainly distressing the environment, and thus the development of new eco-friendly lubricant formulation is a strong need. The lube oil majorly contains base oil in large proportion and a small amount of additives percentage [1]. Thus vegetable oil is the potential feedstock for the development of biolubricants providing higher biodegradability and low ecotoxicity. Besides, the other advantages of vegetable oil include high viscosity, low volatility, and high viscosity versus temperature relationship. However, vegetable oil possesses low thermal and oxidative stability, limiting its applications as lubricating oil [2, $3]$. The poor oxidative and thermal stability of vegetable oil leads to the formation of sludge, deposits and corrosive byproducts that hinders their performance as lubricating oil in industries [4]. Therefore, vegetable oil's improved oxidative and thermal stability is essential for its utilization as lubricating oil. Their fatty acid profile decides the thermal and oxidation stability of the vegetable oil. Greater the unsaturation present in the vegetable oil more is the oilprone to oxidize [5]. Thus, the mechanism of vegetable oil oxidation has been widely researched [2-8]. The process of oxidation involves a free radical mechanism. Firstly, molecular oxygen forms a hydroperoxide radical followed by oxidation. The byproducts formed during the oxidation process leads to chemical and physical changes, which will have a remarkable effect on the lubrication mechanism [5].

However, antioxidants can prevent oxidation by protecting the lubricant from oxidative degradation, fulfilling the oil requirement for industrial standards [7, 9]. Previous literature has reported different antioxidants like hydroxylamines, primary and secondary antioxidants, alkyl radical scavengers [10]. Most of the additives used are either primary antioxidants or chain-breaking radical scavengers or secondary antioxidants like oxygen scavengers or peroxide decomposers that terminate the oxidation process. Thus, different antioxidants additives are added to the mineral base oil, vegetable-based or synthetic lubricants to increase their oxidative stability, such as tocopherols, propyl gallate (PG), ascorbyl palmitate, butylated hydroxyl anisole, butylated hydroxyl toluene, mono-tert-butylhydroquinone may be used to formulate the environmental friendly lubricant $[11,12]$. Therefore, vegetable oil serves as a raw material for the production of biolubricants. They are either utilized directly or by chemical modification to prepare biolubricants [13-15].
The greater flexibility of vegetable oil as lubricant has been best achieved through a chemical transformation like epoxidation, esterification, transesterification. In the past, several research papers had been published for the epoxidation of $-\mathrm{C}=\mathrm{C}-$ in triglycerides to obtain biolubricants [16-25]. Suprakash and his group effectively utilized the WCO from palm oil to prepare biodiesel and alternative eco-friendly fuels and lubricant via catalytic transesterification process using sodium hydroxide as a catalyst. The tribological results indicate that the coefficient of friction has been considerably reduced by $43 \%$ and the wear rate by $71 \%$ [16]. Singh et al. developed biolubricant by epoxidation of Michelia Champaca and then doped with $\mathrm{CeO}_{2}$. He found the maximum increment in viscosity, flash point and tribological properties have been significantly reduced [17]. Samidin and his coworkers successfully synthesized hyperbranched nonaoleate trimethylolpropane as a biolubricant showing a good friction coefficient, high viscosity, higher pour point, high oxidative stability and flash point [18]. Afifah et al. similarly prepared a biolubricant by lipase-catalyzed transesterification of palm oil. The biolubricant has shown superior viscosity and friction properties compared to the commercial lubricant available [19]. Moreira et al. prepared green lubricant using Moringa Oleifera by esterification with polyols, trimethylolpropane and pentaerythritol. The prepared samples have been non-toxic and have higher viscosity indices and lower melting points [20, 21]. Borugadda et al. developed biolubricant by transesterifying soybean waste cooking oil into methyl ester followed by epoxidation reaction. Paul et al. has shown extensive thermophysical analysis by determining refractive index, free fatty acid value, iodine value etc., of waste cooking soybean oil. Thus, the biolubricant has shown to be a potential substitute over conventional feedstock for industrial applications [22-24].

So far, major work reported is based on chemically modified waste cooking oil that has been greatly utilized to prepare biolubricant. For example, Dabai et al. have designed biolubricant by epoxidation of waste cooking palm oil. The biolubricant produced is renewable, biodegradable and ecofriendly [25]. Bashiri et al. has reported a similar study by chemically modifying sunflower waste cooking oil to prepare biolubricant as a potential feedstock over mineral oil for industrial application [26]. Madankar et al. have given a green approach for preparing biolubricant with improved tribological properties from epoxidized canola oil using amberlite IR 120 as catalyst followed by ring-opening with different alcohols [27]. Similarly, Jahromi et al. produced a biolubricant having better physicochemical properties from the reaction of WCO and cyclic oxygenated hydrocarbons via hydrolysis, dehydration, Friedel-Crafts alkylation, and hydrotreatment [28]. Thus, in general, biolubricant has shown numerous advantages compared to conventional mineral oil, including biodegradability, low toxicity, lubrication 
performance, and minimum effect on the environment and human health [29]. Thus, plant-based crops are considered to be the sustainable alternative for the development of biolubricants. Still, their high cost of production and requirement of a large area for cultivation has been the major shortcoming in developing biolubricants from vegetable oil. Thus, the need for alternative renewable resources to produce biolubricants is in great demand [30,31]. Therefore, waste cooking oil is a promising alternative as it is cheaper, recyclable and sustainable than fresh vegetable oil [32]. Presently, about 18 million tons of waste cooking oil has been produced by restaurants and food industries worldwide. Besides some physical and chemical changes taking place in the oil due to frying, it exhibits other properties of vegetable oil, which makes them unfit for human consumption but suitable for the production of biolubricants [33]. Waste cooking oil contains triglycerides of unsaturated fatty acid and glycerol. Therefore, waste cooking oil is considered a sustainable source for producing low-cost biolubricants [34, 35].

However, due to the low oxidative stability of the waste cooking oil, natural antioxidant curcumin has been added to overcome the shortcomings like thermal and oxidation stability. Differential thermal analysis (DTA) has shown that curcumin is thermally stable up to $249^{\circ} \mathrm{C}$ [36]. It is turmeric yellow, an orange-colored crystalline compound soluble in an organic solvent but insoluble in water [37]. The natural dye curcumin is obtained from the turmeric plant (Curcuma longa) has annual world consumption of 300,000 tons. It has found many applications in dyes, COVID-19 immunity-boosting medication, herbs and spice in the food industry [38]. So far, a vast literature has been reported where waste cooking oil, has been extensively utilized as a biolubricant via chemical modification. Whereas, in the present research, a cost-effective and straight forward approach has been developed by directly utilizing curcumin extracted waste cooking oil for biolubricant formulation without any chemical modification. Further, the biolubricant has been prepared by blending the waste cooking oil in different compositions $(10 \%, 20 \%, 30 \% \mathrm{v} / \mathrm{v})$ with $\mathrm{N}-150$ mineral base oil. The thermophysical analysis, rheological and tribological studies of the prepared biolubricant has been evaluated by standard ASTM methods, and the results have been reported. The thermophysical properties of waste cooking oil have been listed in Table 1.

\section{Materials and Method}

\section{Materials}

Curcumin powder was obtained from a local market, and soybean waste cooking oil was received from the hostel kitchen of the university campus, Dehradun. Ethanol
Table 1 Thermophysical properties of waste cooking oil (WCO) and curcumin extracted WCO

\begin{tabular}{lll}
\hline Thermophysical properties & $\begin{array}{l}\text { Waste cooking } \\
\text { oil (WCO) }\end{array}$ & $\begin{array}{l}\text { Curcumin } \\
\text { extracted } \\
\text { WCO }\end{array}$ \\
\hline Kinematic viscosity at $40{ }^{\circ} \mathrm{C}(\mathrm{cSt})$ & 34.0 & 33.1 \\
Kinematic viscosity at $100{ }^{\circ} \mathrm{C}(\mathrm{cSt})$ & 7.9 & 7.7 \\
Viscosity index & 217 & 214 \\
Pour point $\left({ }^{\circ} \mathrm{C}\right)$ & -16 & -20 \\
Flash point $\left({ }^{\circ} \mathrm{C}\right)$ & 305 & 308 \\
\hline
\end{tabular}

(AR 99.9\%) was purchased from SDFCL and was used as received. Methanol (AR 99.9\%) was purchased from Sigma-Aldrich, Bangalore. The mineral base oil N-150 was collected from RBM oil corporation ltd., Pune, Maharashtra.

\section{Preparation of Biolubricants}

Curcumin extracted waste cooking oil $(0.5 \mathrm{wt} \%)$ was prepared by adding $0.5 \mathrm{~g}$ turmeric powder in $100 \mathrm{ml}$ of waste cooking oil. Then it was heated for an hour till the color of the oil changed to yellow. The oil was cooled to room temperature, filtered, and further used to prepare biolubricants. Waste cooking oil containing curcumin was then added in three different compositions $(10 \%, 20 \%, 30 \%$ vlv) to the mineral base oil $(\mathrm{N}-150)$ and was re-evaluated for thermophysical, tribological and rheological analysis [39-41].

\section{Performance Evaluation}

\section{Antioxidant Behaviour of Curcumin}

The antioxidant behaviour of the curcumin extracted waste cooking oil was confirmed by performing two different experiments. (i) The reaction was initiated in which curcumin extracted $\mathrm{WCO}$ was heated in the presence of air at $100{ }^{\circ} \mathrm{C}$ for $6 \mathrm{~h}$. (ii) The reaction of curcumin extracted WCO was carried out in the presence of benzoyl peroxide at $100{ }^{\circ} \mathrm{C}$ for $6 \mathrm{~h}$. The resultant product from both experiments was analyzed by FT-IR spectroscopy to confirm their antioxidant activity.

\section{Viscosity Index Evaluation (VI)}

The Cannon-Fenske Opaque Viscometer was used to determine the kinematic viscosity of the biolubricants in different compositions $(10 \%, 20 \%, 30 \%$ vlv) by standard ASTM D445 method at 40 and $100{ }^{\circ} \mathrm{C}$ [42]. 


\section{Pour Point Evaluation (PP)}

The pour point of the formulated biolubricant was analyzed in different concentrations $(10 \%, 20 \%, 30 \% \mathrm{vlv})$ with the help of the standard ASTM D97 method [43].

\section{Flash Point and Fire Point}

The flash point and fire point of a formulated biolubricant was determined using the Pensky-Martens flash point tester by ASTM D93 method.

\section{Rheological Analysis}

The rheology of the biolubricant was examined by using Anton Paar rheometer MCR-72. The relationship between dynamic viscosity, shear rate and shear stress of the formulated biolubricant was studied at $40{ }^{\circ} \mathrm{C}$ and $100{ }^{\circ} \mathrm{C}$.

\section{Tribological Evaluation}

The antiwear performance of the formulated biolubricant was analyzed in terms of wear scar diameter (WSD) and coefficient of friction (COF) by the standard four-ball wear test apparatus (FBWT) following the ASTM D4172 method. Here, $40 \mathrm{Kgf}$ load $(392 \mathrm{~N})$ at $75^{\circ} \mathrm{C}$ for an hour was applied to measure wear scar diameter (WSD). The rotating speed was maintained at $1200 \mathrm{rpm}$ and the diameter of the ball was $12.7 \mathrm{~mm}$.

\section{Cost Analysis}

The calculated cost of formulated biolubricant as compared to mineral base oil according to the Indian local market was analyzed.

\section{Result and Discussion}

Waste cooking oil has been preferred due to its low cost, non-edible, renewable feedstock with higher viscosity index, low volatility, good lubricity, higher flash point, making it a suitable alternative for the preparation of biolubricant [39-41]. Herein, curcumin was extracted as a natural antioxidant in waste cooking oil from turmeric powder and used to formulate biolubricant by blending in different compositions viz $10 \%, 20 \%, 30 \% \mathrm{v} / \mathrm{v}$ to the mineral base oil N-150 $[38,44]$. The chemical components present in WCO and turmeric powder are shown in Fig. 1.

Antioxidant behaviour of the curcumin in WCO was confirmed by prolong heating of WCO in the presence of benzoyl peroxide or under air atmosphere. It was observed that no polymerization reaction was taking place which was further confirmed by FT-IR spectroscopy. The unsaturated double bonds in curcumin extracted WCO was maintained and observed at $3004 \mathrm{~cm}^{-1}, 1659 \mathrm{~cm}^{-1}$ for $=\mathrm{C}-\mathrm{H}$ and $-\mathrm{C}=\mathrm{C}-$ respectively. Results are depicted in Fig. 2.

The thermophysical property of the biolubricant was evaluated at lower temperature condition. It was observed that the formulated biolubricant shows a depression in pour point compared to the mineral base oil (Fig. 3a). It was noted that, WCO and curcumin extracted WCO shows a pour point at $-16{ }^{\circ} \mathrm{C}$ and $-20{ }^{\circ} \mathrm{C}$ respectively (refer Table 1), whereas, curcumin extracted WCO on blending with mineral base oil at a lower concentration $(10 \% \mathrm{v} / \mathrm{v})$, shows a maximum depression to $-30{ }^{\circ} \mathrm{C}$. The depression in pour point was attributed to polar functionality present in curcumin extracted WCO. Also, at a lower temperature, these high molecular weight paraffinic waxes may disperse themselves uniformly in the waste cooking oil formulated with mineral base oil, thus lowering the pour point of biolubricant [45]. Hence, biolubricant shows better pour point depressant property at a lower concentration. Though, the

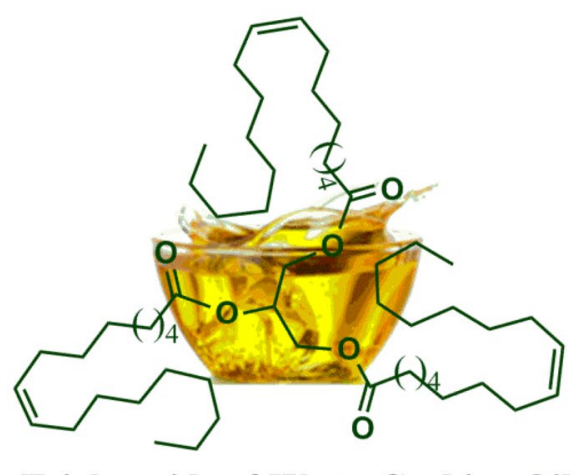

Triglyceride of Waste Cooking Oil

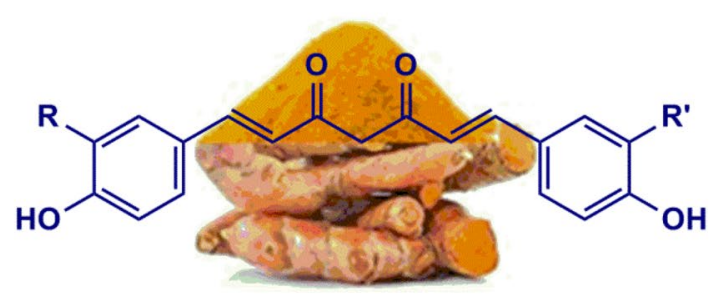

If $\mathbf{R}, \mathbf{R}^{\prime}=\mathbf{O M e}$ for curcumin, $\mathbf{R}=\mathbf{H}$ for demethoxy curcumin, $\mathbf{R}, \mathbf{R}^{\prime}=\mathbf{H}$ for bisdemethoxy curcumin Curcuminoids from Turmeric powder

Fig. 1 General chemical structure of WCO and curcumin 


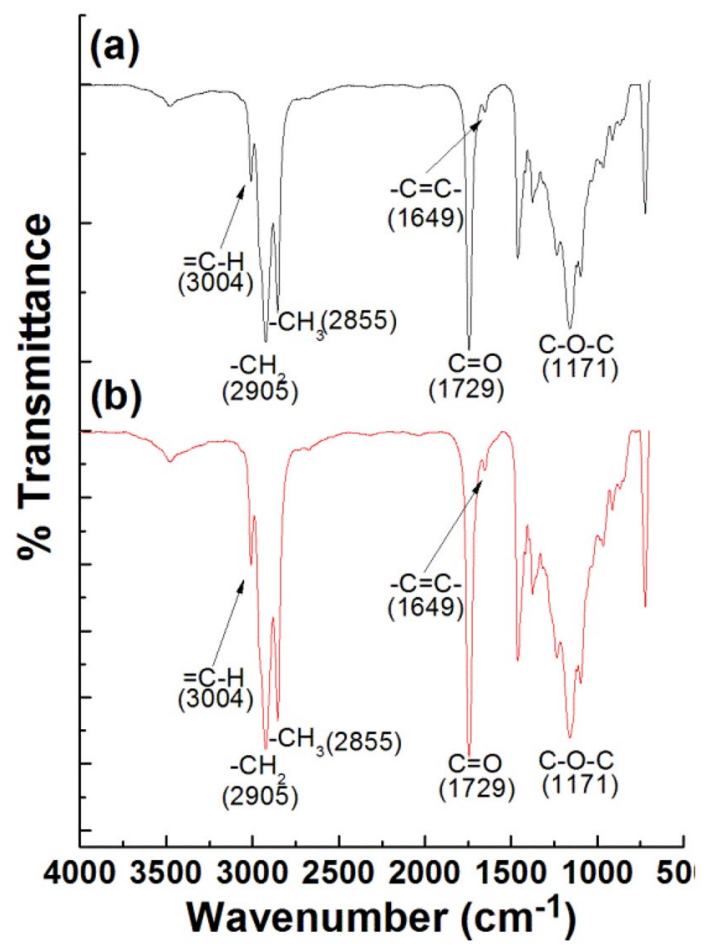

Fig. 2 FT-IR spectrum of curcumin extracted waste cooking oil: a heating under air, $\mathbf{b}$ heated in presence of benzoyl peroxide

pour point depressant property of formulated oil is found to be better than mineral base oil (N-150) at all concentrations.

Viscosity index measures the change in viscosity with temperature. The data indicates the viscosity of biolubricant increases compare to the mineral base oil (N-150). It is evident that, with the increase in the concentration of curcumin based WCO in mineral base oil (N-150), the value of the viscosity index increases (Fig. 3b). The result indicates that $30 \%$ concentration of WCO in N-150 base oil shows a higher viscosity index. This increment in viscosity index at higher concentrations possibly due to curcuminoids and the higher molecular weight of WCO $(\sim 876-920 \mathrm{~g} / \mathrm{mol})$ present in biolubricant. Thus, a higher viscosity index makes the biolubricant more suitable at a wider range of temperatures. Biolubricant with $30 \%$ concentration is more feasible at higher temperatures as it forms a stable lubricating film between the contact surfaces. A simultaneous decrease in viscosity of WCOs with temperature has been observed, but the reduction in the viscosity is maintained at a higher temperature as compared to the mineral oil. The viscosity of the WCOs decreases as the temperature increases because the kinetic energy of the molecules increases with the rise in temperature, which lowers the internal resistance of the WCOs. The variation of the viscosity with temperature for WCOs has been reflected in the Figs. $4 \mathrm{a}-\mathrm{c}$.

Comparative data of the thermophysical properties of the mineral base oil and formulated biolubricant are shown in Table 2. Flash temperature parameter was evaluated for the formulated biolubricant. It was found that the flash point temperature of WCO is higher than mineral oil (N-150), hence showing better ignition property of biolubricant as compare to the mineral base oil (Fig. 5). Thus, WCO based biolubricant is more compatible at higher temperature as compared to conventional mineral oil. This may be due to, at such a higher temperature, the vapour pressure of the liquid is so high that the concentration of flammable or combustible liquid in air increases. Hence, temperature determines the concentration of vapours in liquid air.

\section{Rheological Analysis}

The rheological study of the formulated biolubricant WCO1, WCO-2 and WCO-3 (10\%, 20\%, 30\% v/v) have been done using MCR-72 Anton paar. The biolubricant was prepared
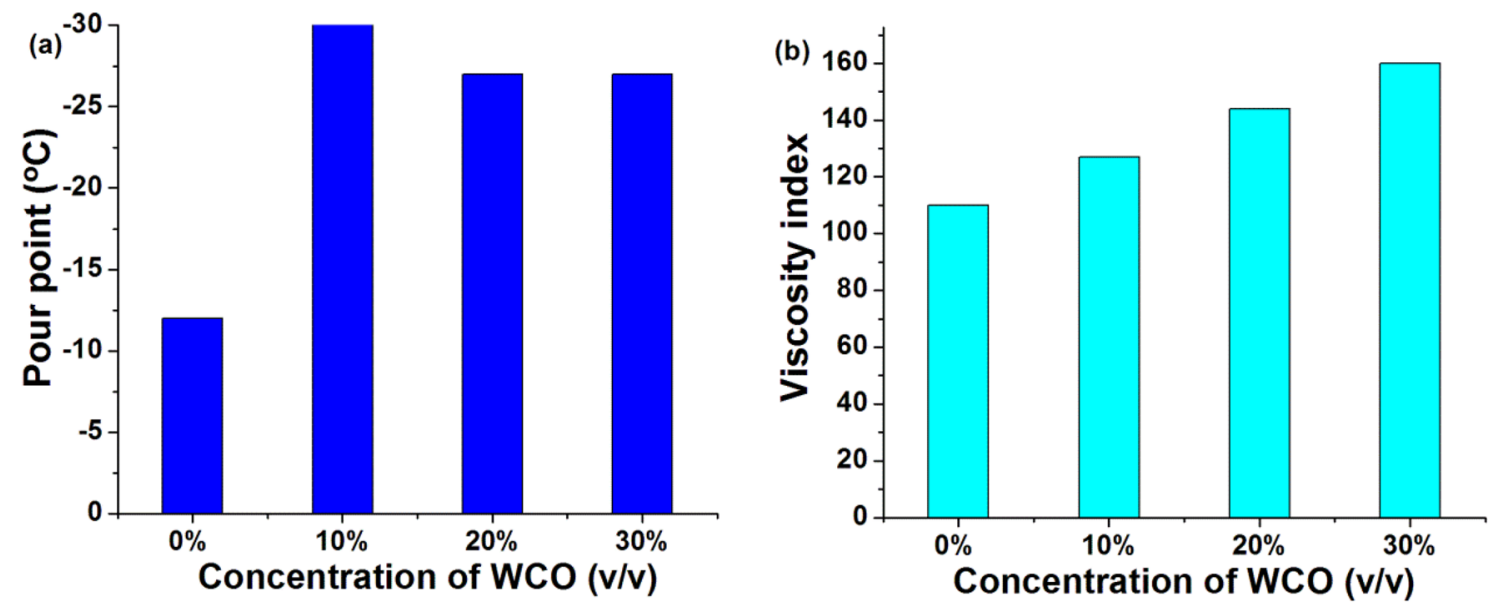

Fig. 3 Thermophysical evaluation of biolubricant a Pour point v/s concentration of WCO, $\mathbf{b}$ Viscosity index v/s concentration of WCO 

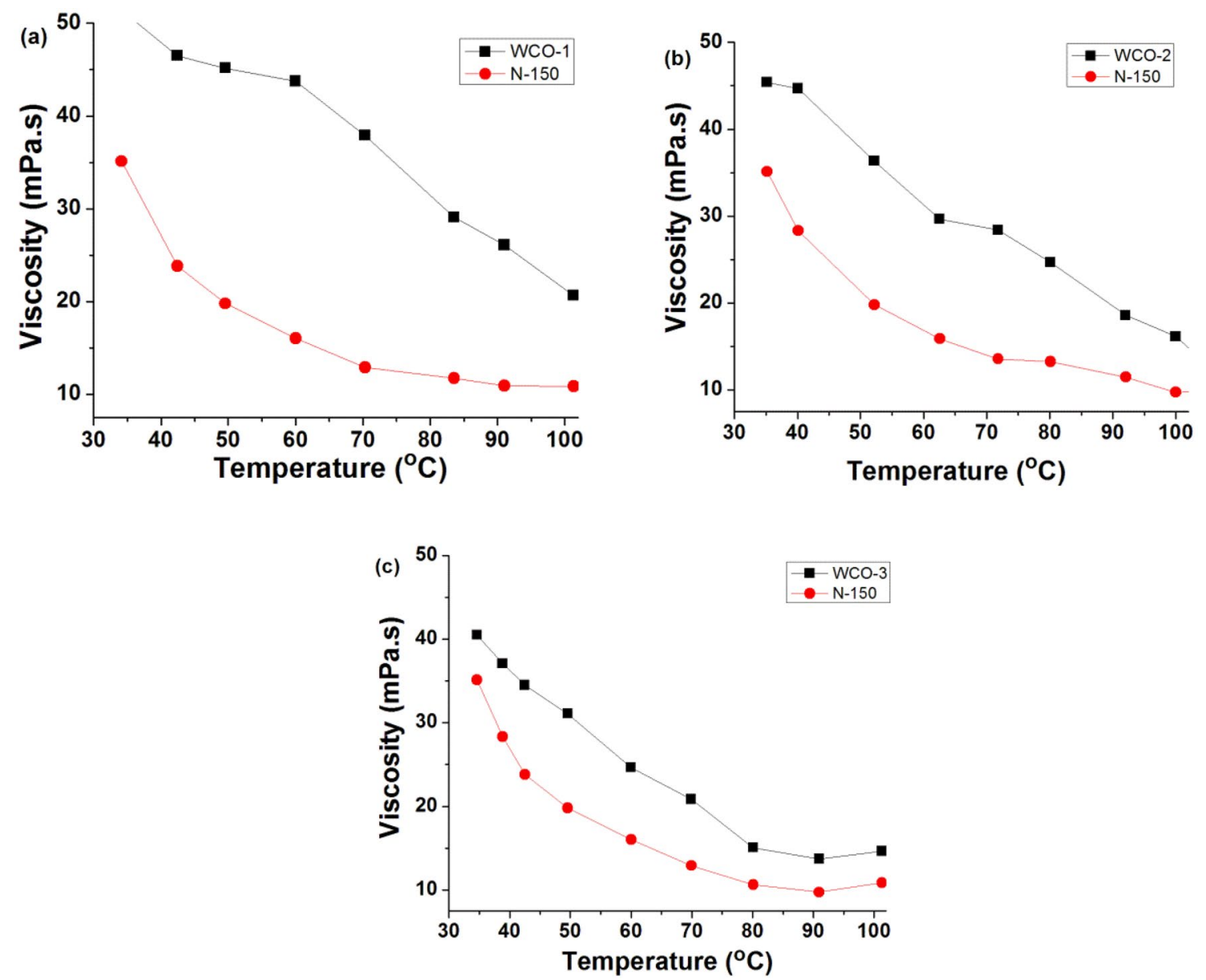

Fig. 4 Viscosity v/s temperature curves a WCO-1 at 10\%, b WCO-2 at 20\%, and c WCO-3 at 30\% concentration

Table 2 Thermophysical properties of formulated biolubricant in different concentration

\begin{tabular}{lllll}
\hline $\begin{array}{l}\text { Thermophysical } \\
\text { properties }\end{array}$ & Base oil (N-150) & WCO-1 & WCO-2 & WCO-3 \\
\hline $\begin{array}{l}\text { Kinematic viscosity } \\
\text { at } 40{ }^{\circ} \mathrm{C}(\mathrm{cSt})\end{array}$ & 31.5 & 29.5 & 29.2 & 29.0 \\
$\begin{array}{l}\text { Kinematic viscosity } \\
\text { at } 100{ }^{\circ} \mathrm{C}(\mathrm{cSt})\end{array}$ & 5.4 & 5.5 & 5.7 & 6.0 \\
$\begin{array}{l}\text { Viscosity index } \\
\text { Pour point }\left({ }^{\circ} \mathrm{C}\right)\end{array}$ & 110 & 127 & 144 & 160 \\
Flash point $\left({ }^{\circ} \mathrm{C}\right)$ & 225 & -30 & -27 & -27 \\
\hline
\end{tabular}

by blending the curcumin based waste cooking oil in N-150 mineral base oil. The rheological study was done to evaluate the flow behaviour of the biolubricant by varying the shear rate and keeping the temperature constant at $40{ }^{\circ} \mathrm{C}$ and $100{ }^{\circ} \mathrm{C}$. The rheological behaviour of the biolubricant was studied, and results are summarized in Figs. 6, 7 and 8. It was observed that the formulated biolubricant shows the non-Newtonian behaviour with a rise in shear rate.

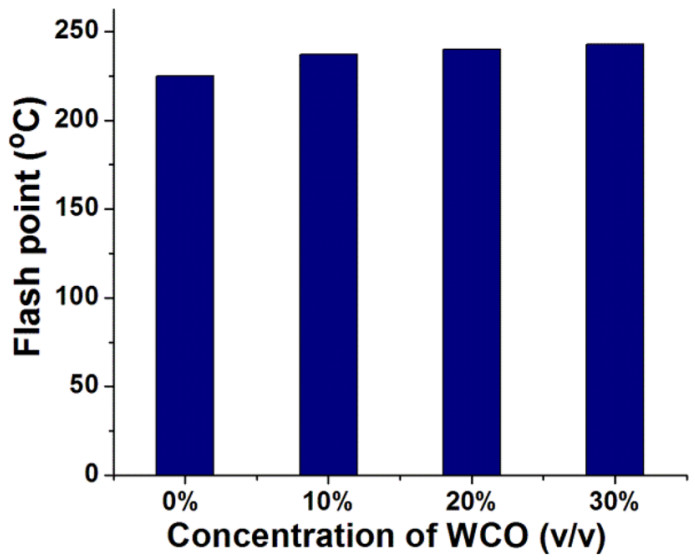

Fig. 5 Variation of flash point v/s concentration of waste cooking oil in biolubricant

This non-Newtonian behaviour of biolubricant is also correlated with shear stress versus shear rate curve (Figs. 9, 10 and 11). With an increase in shear rate, the viscosity 

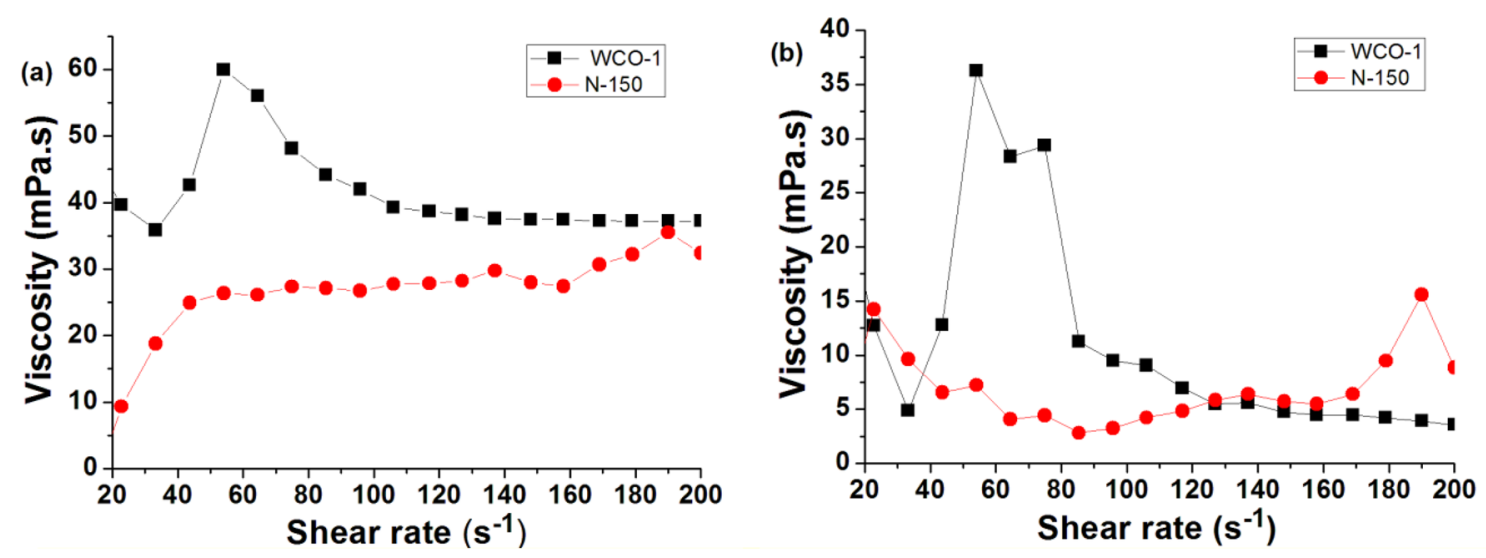

Fig. 6 Rheological curve of viscosity v/s shear rate for WCO- 1 a at $40{ }^{\circ} \mathrm{C}$ and $\mathbf{b}$ at $100{ }^{\circ} \mathrm{C}$
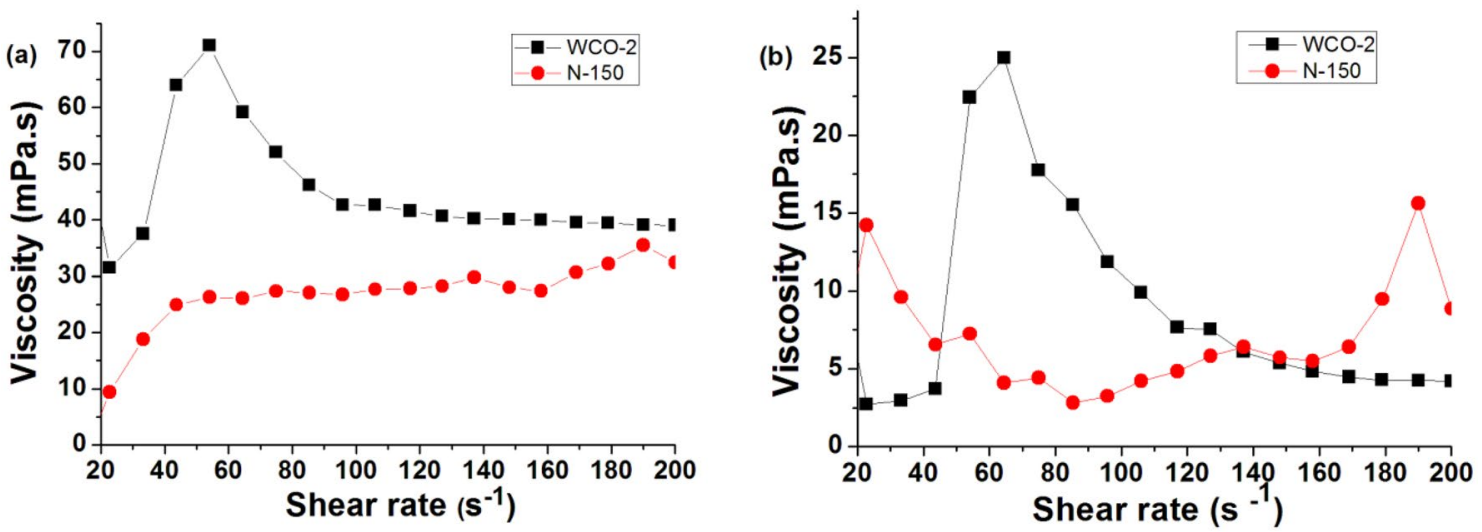

Fig. 7 Rheological curve of viscosity v/s shear rate for WCO-2 a at $40{ }^{\circ} \mathrm{C}$ and $\mathbf{b}$ at $100{ }^{\circ} \mathrm{C}$
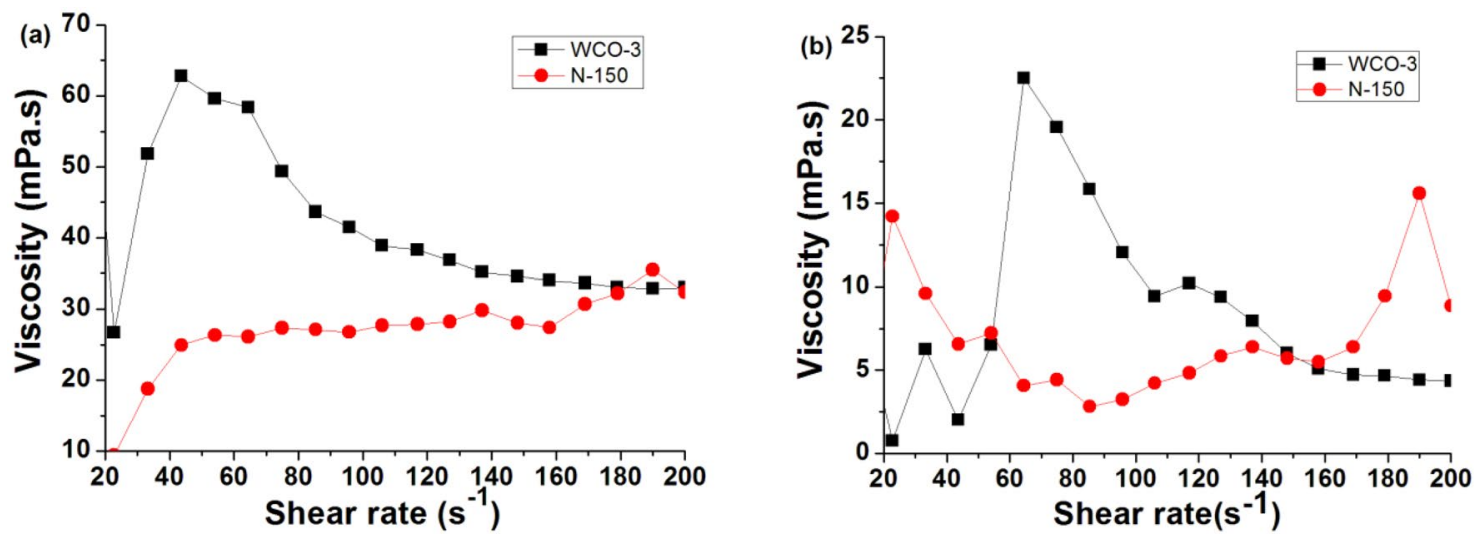

Fig. 8 Rheological curve of viscosity v/s shear rate for WCO-3 a at $40{ }^{\circ} \mathrm{C}$ and $\mathbf{b}$ at $100{ }^{\circ} \mathrm{C}$

of the WCOs was increased compared to the mineral base oil. From Figs. 6, 7 and 8, it is clear that at a lower shear rate $\left(20-60 \mathrm{~S}^{-1}\right)$, viscosity is first increasing and then as the shear rate increases $\left(65-200 \mathrm{~S}^{-1}\right)$, viscosity decreases. Thus, biolubricant is showing Non-Newtonian behaviour. Further, it is also observed that behaviour has been transitioned from shear thickening to shear thinning with an increase in shear rate. This transformation in behaviour from shear thickening to shear thinning has been attributed to, as the shear rate increases, viscosity increases indicating a less deformation 

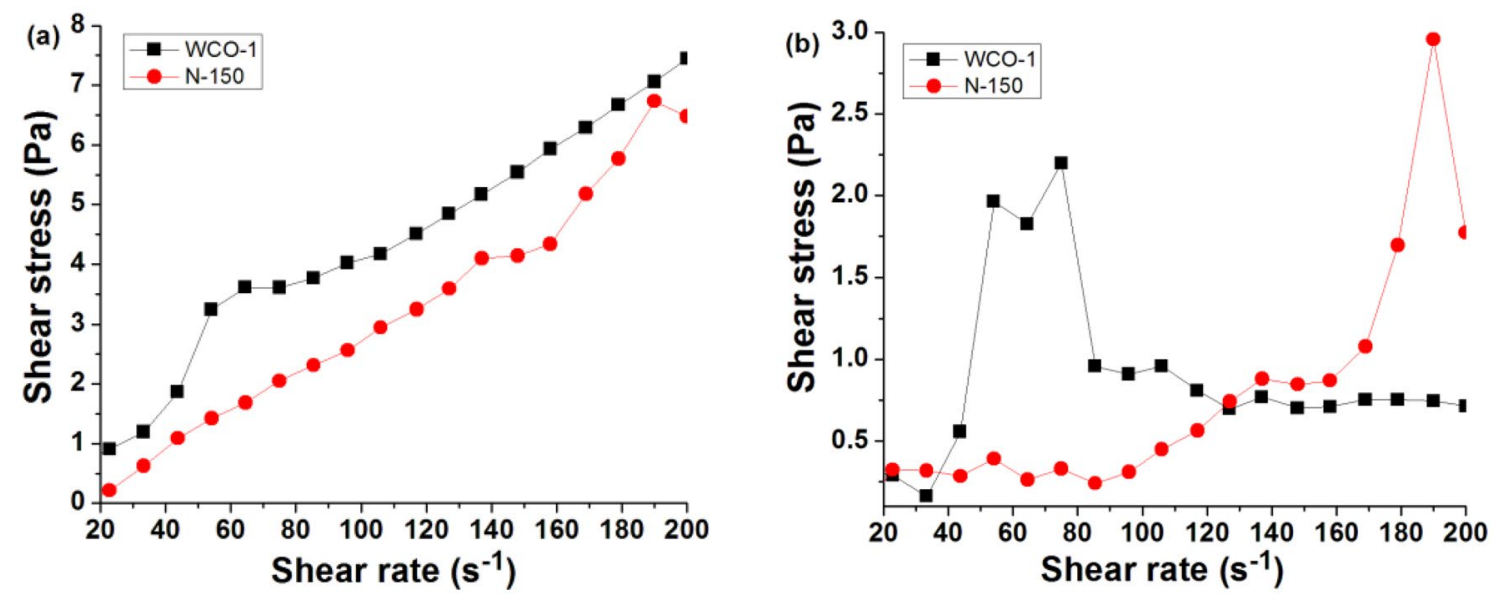

Fig. 9 Rheological curve of shear stress v/s shear rate for WCO- 1 a at $40{ }^{\circ} \mathrm{C}$ and $\mathbf{b}$ at $100{ }^{\circ} \mathrm{C}$
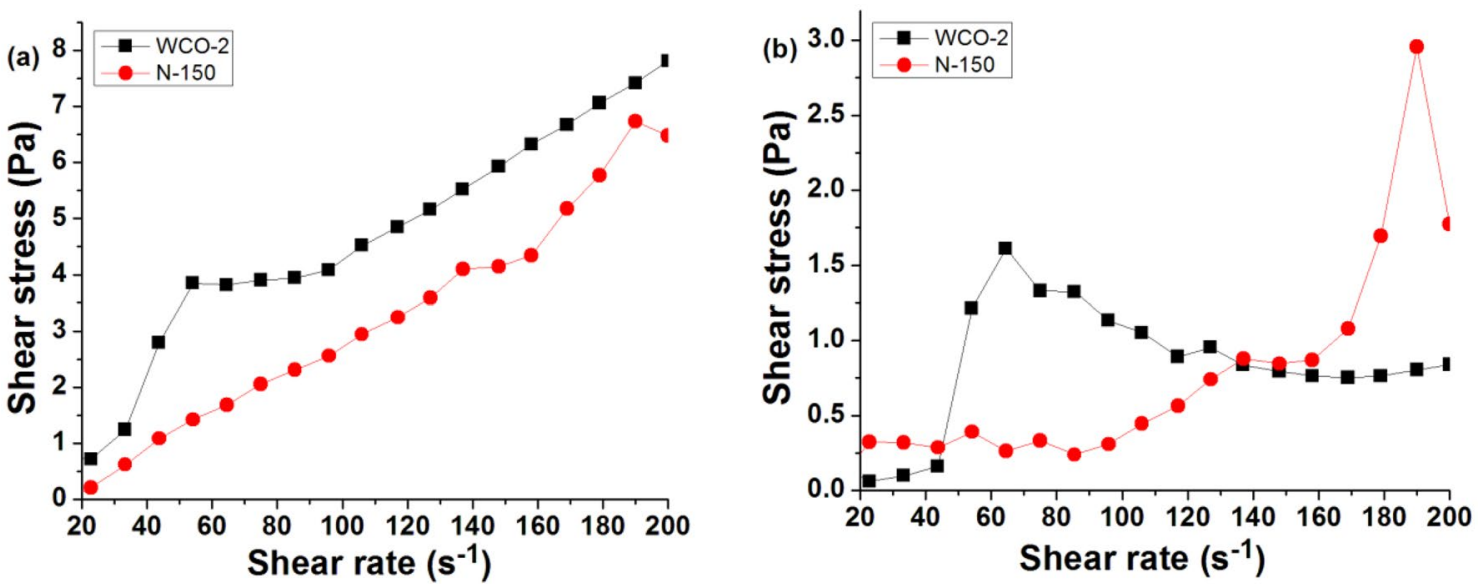

Fig. 10 Rheological curve of shear stress v/s shear rate for WCO-2 a at $40{ }^{\circ} \mathrm{C}$ and $\mathbf{b}$ at $100{ }^{\circ} \mathrm{C}$
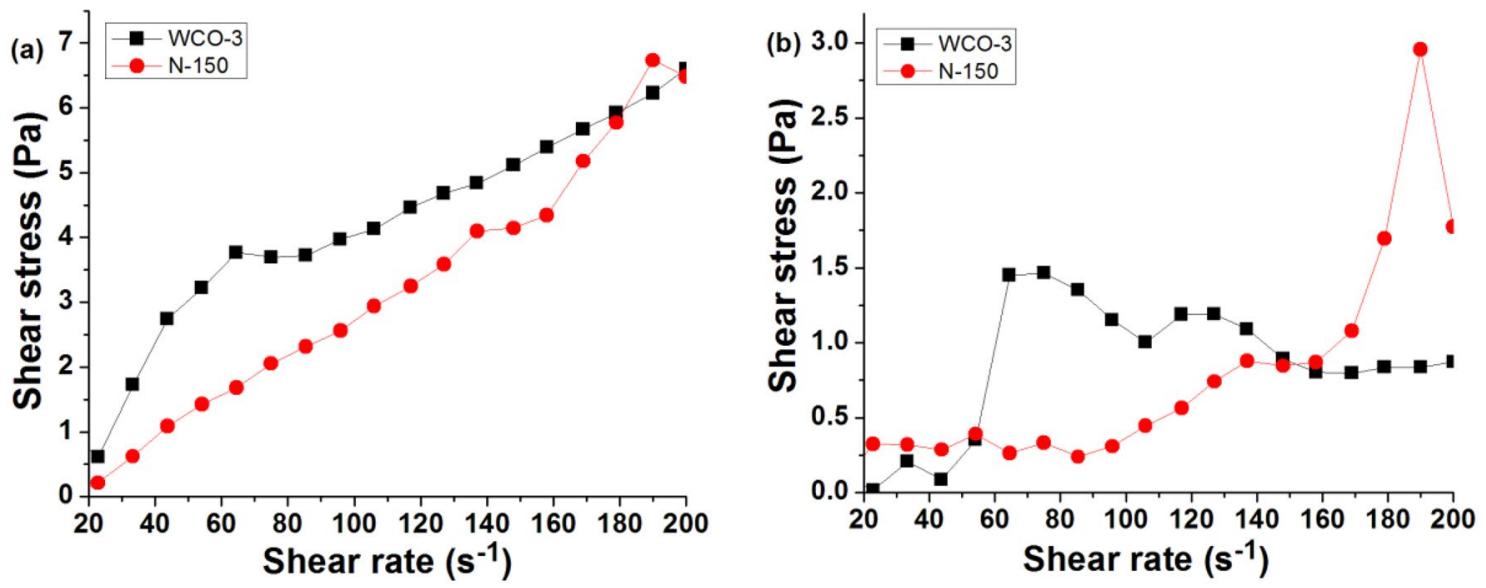

Fig. 11 Rheological curve of shear stress v/s shear rate for WCO-3 a at $40{ }^{\circ} \mathrm{C}$ and $\mathbf{b}$ at $100{ }^{\circ} \mathrm{C}$ 
in the wax molecules. But as shear rate increases, wax molecules get deformed and move with the direction of shear, thereby, decreasing the viscosity of the lubricant.

\section{Tribological Analysis}

The tribological properties of WCO-3 having a 30\% concentration of curcumin doped waste cooking oil show high viscosity index as compare to WCO-1, WCO-2 with $10 \%$ and $20 \%$ concentration (Fig. 3b). Therefore, tribological properties of WCO-3 was determined in terms of wear scar diameter and coefficient of friction through the standard four-ball wear test method (ASTM D4172). It was observed that wear scar diameter and coefficient of friction was significantly reduced as compared to the mineral base oil. The antiwear performance of the biolubricant has shown a $16 \%$ reduction in wear scar diameter, whereas the coefficient of friction has reduced by $32 \%$ compared to the mineral base oil N-150. Thus, the film formed by the lubricant between the two contacting surfaces experiences friction through physical and chemical bonding protects the surface from tribo-chemical processes. The better antiwear performance indicates the formation of the strong film by the lubricant. The results are summarized in Table 3.

\section{Cost Effective Analysis}

The cost for the preparation of biolubricant depends on different factors like feedstock, manpower and transformation cost. Amongst all, feedstock plays a crucial part in making the process cost-effective and reducing the price by $60-70 \%$ [46]. In the past, vegetable oil has drawn considerable attention in the preparation of biofuels and biolubricant [47, 48]. In this process, edible and non-edible oil has been heavily utilized to prepare lubricant, which has ultimately increased the lubricant cost. Hence, we aimed to choose non-edible feedstock, which paves the way for using waste cooking oil. This non-edible waste vegetable oil is unfit for consumption in human beings and is readily available at lower prices in the local market and restaurants. Thus, using waste cooking oil is cheaper, eco-friendly and renewable waste biomass to prepare biolubricant [49]. The current prices of the vegetable feedstock available in the Indian local market have been summarized in Fig. 12. The calculated cost of the

Table 3 Tribological properties of formulated biolubricant

\begin{tabular}{llll}
\hline S. No & Lubricant & WSD $(\mathrm{mm})$ & COF $(\mu)$ \\
\hline 1 & N-150 & 0.685 & 0.117 \\
2 & WCO-3 & 0.573 & 0.080 \\
\hline
\end{tabular}

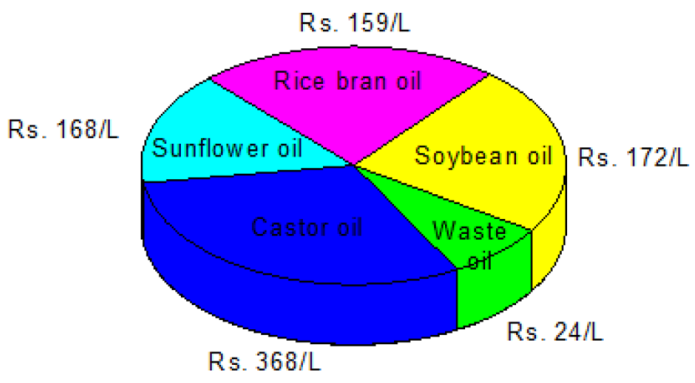

Fig. 12 Comparative cost of feedstock for preparation of biolubricants

formulated biolubricant as compared to mineral base oil is given in Table 4.

\section{Conclusion}

The above study has given a simple, cost-effective, and sustainable green approach to prepare a biolubricant from waste cooking oil. Curcumin was used as a natural antioxidant that will further prevent the oxidation of waste cooking oil and its antioxidant activity was confirmed by FT-IR analysis. It was observed that the viscosity index value has considerably increased with an increase in the concentration of WCO in mineral oil whereas; biolubricant with lowest concentration shows a maximum depression in pour point. It was also observed that the flash point temperature of the WCOs is higher as compared to the mineral base oil. Thus, enhancement in thermophysical properties of the WCOs makes the biolubricant feasible at extreme temperature conditions. A rheological study has confirmed the non-Newtonian behaviour of the biolubricant, which is in agreement with viscosity index values. Moreover, tribological analysis indicates that WCO-3 shows a significant reduction in wear scar diameter and coefficient of friction with respect to the mineral base oil. The significance of the present work lies in the fact that a biolubricant has been prepared by a straightforward method without undergoing any chemical modification of WCO and is compatible enough with conventional mineral oil. Thus, WCO can be effectively utilized as a potential feedstock for the cleaner production of green biolubricant.

Table 4 Cost of the prepared biolubricant in different compositions

\begin{tabular}{lll}
\hline S.No & Biolubricant & $\begin{array}{l}\text { Cost } \\
\text { per litre } \\
\text { (INR) }\end{array}$ \\
\hline 1 & Mineral oil & 90 \\
2 & WCO-1 & 83 \\
3 & WCO-2 & 77 \\
4 & WCO-3 & 70 \\
\hline
\end{tabular}


Acknowledgements The authors kindly acknowledge IIT Delhi, IIT Roorkee and CSIR-IIP Dehradun for extending the support in molecular characterization. We would like to thank Dr. Jyoti Porwal and Dr. Raj K. Singh for their support in completing the project. Further, we thank DIT University for the award of research fellowship to Nisha Singh.

Data Availability The supporting data are presented in the manuscript itself; hence no supplementary data are attached.

\section{Declarations}

Conflict of interest The authors declare no competing interests.

Ethical Approval This manuscript has not been published and is not under consideration for publication elsewhere. As the corresponding author, I confirm that the manuscript has been read and approved for submission by all the named authors.

\section{References}

1. Luna, F.M.T., Rocha, B.S., Rola, E.M., Albuquerque, M.C.G., Azevedo, D.C.S., Cavalcante, C.L.: Assessment of biodegradability and oxidation stability of mineral, vegetable and synthetic oil samples. Ind. Crops. Prod. 33, 579-583 (2011)

2. Erhan, S.Z., Sharma, B.K., Perez, J.M.: Oxidation and low temperature stability of vegetable oil-based lubricants. Ind. Crops. Prod. 24, 292-299 (2006)

3. Campanella, A., Rustoy, E., Baldessari, A., Baltanás, M.A.: Lubricants from chemically modified vegetable oils. Bioresour. Technol. 101, 245-254 (2010)

4. Duangkaewmanee, S., Petsom, A.: Synergistic and antagonistic effects on oxidation stability of antioxidants in a synthetic ester based oil. Tribo. Int. 44, 266-271 (2011)

5. Fox, N.J., Stachowiak, G.W.: Vegetable oil-based lubricants - a review of oxidation. Tribol. Int. 40, 1035-1046 (2007)

6. Hassel, R.L.: Thermal analysis: an alternative method of measuring oil stability. J. Am. Oil. Chem. Soc. 53, 179-181 (1976)

7. Wanasundara, P., Shahidi, F (2005) Antioxidants: science technology and applications in Bailey's Industrial Oil and Fat Products, 6th ed. Edible Oil and Fat Products Chemistry Properties and Health Effects. Shahidi F. (ed.) Vol. 1, pp. 431-489. Wiley Hoboken, NJ

8. Pardauil, J.J.R., Souza, L.K.C., Molfetta, F.A., Zamian, J.R., Rocha, G.N., da Costa, C.E.F.: Determination of the oxidative stability by DSC of vegetable oils from the amazonian area. Bioresour. Technol. 102, 5873-5877 (2011)

9. Garcia-Perez, M., Adams, T.T., Goodrum, J.W., Das, K.C., Geller, D.P.: DSC studies to evaluate the impact of bio-oil on cold flow properties and oxidation stability of bio-diesel. Bioresour. Technol. 101, 6219-6224 (2010)

10. Thomas, R., Dexter, M., King, R.E III.: Antioxidants, polymers. In Encyclopedia of Chemical Technology; Kirk, R. E., et al., Eds.; Wiley: Hoboken, NJ3:102-134 (2002)

11. Hras, A.R., Hadolin, M., Knez, Z., Bauman, D.: Comparison of antioxidative and synergistic effects of rosemary extract with $\alpha$ tocopherol, ascorbyl palmitate and citric acid in sunflower oil. Food. Chem. 71, 229-233 (2002)

12. Merrill, L.I., Pike, O.A., Ogden, L.V., Dunn, M.L.: Oxidative stability of conventional and high-oleic vegetable oils with added antioxidants. J. Am. Oil. Chem. Soc. 85, 771-776 (2008)
13. Salimon, J., Salih, N., Yousif, E.: Biolubricants. Raw materials, chemical modifications and environmental benefits. Eur. J. Lipid. Sci. Technol. 112, 519-530 (2010)

14. Hahn, S., Dott, W., Eisentraeger, A.: Characterization of ageing behavior of environmentally acceptable lubricants based on trimethyl propane ester. J. Synth. lubr. 23, 223-236 (2006). https:// doi.org/10.1002/jsl.24

15. Pettersson, A.: Tribological characterization of environmentally adapted ester based fluids. Tribol Int. 36, 815-820 (2006)

16. Samanta, S., Sahoo, R.: Waste cooking (Palm) oil as an Economical Source of Biodiesel production for Alternative Green Fuel and Efficient Lubricant. Bioenerg. Res. 14, 163-174 (2021)

17. Singh, Y., Rahim, E.A.: Michelia Champasa: sustainable novel non-edible oil as nano based biolubricant with tribological investigation. Fuel 282, 118830 (2020)

18. Samidin, S., Salih, N., Salimon, J.: Synthesis and characterization of trimethylolpropane based esters as green biolubricant basestock biointerface. Res. Appl. Chem. 11, 13638-13651 (2021)

19. Afifah, A.N., Syahrullail, S., Wan Azlee, N.I., Che Sidik, N.A., Yahya, W.J.: Abd Rahim E (2019) Biolubricant production from palm stearin through enzymatic transesterification method. Biochem. Eng. J. 148, 178-184 (2019)

20. Moreira, D.R., Chaves, P.O.B., Ferreira, E.N., Arruda, T.B.M., Rodrigues, F.E.A., Neto, J.F.C., Petzhold, C.L., Maier, M.E., Ricardo, N.M.P.: Moringa polyesters as eco-friendly lubricants and its blends with naphthalenic lubricant. Ind. Crops. Prod. 158, 112937 (2020)

21. Owuna, F.J., Dabai, M.U., Sokoto, M.A., Dangoggo, S.M., Bagudo, B.U., Birnin-Yauri, U.A., Hassan, L.G., Sada, I., Abubakar, A.L., Jibrin, M.S.: Chemical modification of vegetable oils for the production of biolubricants using trimethylolpropane: A review. Egypt. J. Pet. 29, 75-82 (2020)

22. Borugadda, V.B., Goud, V.V.: Improved thermal oxidative stability of structurally modified waste cooking oil methyl esters for biolubricant applications. J. Clean. Prod. 112, 4515-4524 (2016)

23. Paul, A.K., Borugadda, V.B., Goud, V.V.: In-situ epoxidation of waste cooking oil and its methyl esters for lubricant applications: characterization and rheology. Lubricants. 9, 27 (2021)

24. Owuna, F.J.: Stability of vegetable based oils used in the formulation of ecofriendly lubricants - a review. Egypt. J. Pet. 29(3), 251-256 (2020)

25. Dabai, M.U., Owuna, F.J., Sokoto, M.A., Abubakar, A.L.: Assessment of quality parameters of ecofriendly biolubricant from waste cooking palm oil. Asian. J. Appl. Chem. Res. 1, 1-11 (2018)

26. Bashiri, S., Ghobadian, B., Soufi, M.D., Gorjian, S.: Chemical modification of sunflower waste cooking oil for biolubricant production through epoxidation reaction. Mater. Sci. Technol. 4, 119-127 (2021)

27. Madankar, C.S., Dalai, A.K., Naik, S.N.: Green synthesis of biolubricant base stock from canola oil. Ind. Crops Prod. 44, 139-144 (2013)

28. Jahromi, H., Adhikari, S., Roy, P., Shelley, M., Hassani, E., Oh, T.S.: Synthesis of novel biolubricants from waste cooking oil and cyclic oxygenates through an integrated catalytic process. ACS. Sustainable. Chem. Eng. 9(40), 13424-13437 (2021)

29. McNutt, J.: Development of biolubricants from vegetable oils via chemical modification. J. Ind. Eng. Chem. 36, 1-12 (2016)

30. Salih, N., Salimon, J.: A review on eco-friendly green biolubricant from renewable and sustainable plant oil sources. Biointerface. Res. Appl. Chem. 11(5), 13303-13327 (2021)

31. Salih, N., Salimon, J.: A review on new trends, challenges and prospects of ecofriendly friendly green food-grade biolubricants. Biointerface Res. Appl. Chem. 12(1), 1185-1207 (2022)

32. Yaakob, Z., Mohammad, M., Alherbawi, M., Alam, Z., Sopian, K.: Overview of the production of biodiesel from Waste cooking oil. Renew. Sustain. Energy. Rev. 18, 184-189 (2013) 
33. Patil, P.D., Gude, V.G., Deng, S.: Biodiesel production from jatrophacurcas, waste cooking, and camelina sativa oils. Ind. Eng. Chem. Res. 48, 10805-10850 (2009)

34. Wang, E.P., Ma, X., Tang, S.Z., Yan, R., Wang, Y., Rily, W.W., Reaney, M.J.T.: Synthesis and oxidative stability of trimethylolpropane fatty acid triester as a biolubricant baseoil from waste cooking oil. Biomass. Bio-energy. 66, 371-378 (2014)

35. Porwal, J., Khatri, P.K., Kaul, S., Behera, B., Atray, N., Jain, S.: Polymer-grafted sulfonated carbon-catalyzed synthesis of $\alpha$-hydroxy ethers as biolubricants from waste vegetable oil. Biomass. Conv. Bioref. (2020). https://doi.org/10.1007/ s13399-020-01047-8

36. Jasim, F., Talib, T.: Some observations on the thermal behaviour of curcumin under air and argon atmospheres. J. Therm. Anal. 38, $2549(1992)$

37. Jasim, F., Talib, T.: Measurement of some spectrophotometric parameters of curcumin in 12 polar and non polar organic solvents. J. Therm. Anal. 39, 156 (1989). https://doi.org/10.1016/ 0026-265X(89)90024-6

38. Talib Issa Al-Omran, T.: The effect of natural antioxidant on the efficiency of lubricant oil. Acta Phys. Pol., A 134, 426-428 (2018)

39. Agarwal, P., Porwal, S.K.: Non-edible/waste cooking oil-derived sustainable green multifunctional copolymeric additives for mineral base oil. Biomass Conv. Bioref. (2021). https://doi.org/10. 1007/s13399-021-01336-w

40. Agarwal, P., Chaudhary, S., Porwal, J., Singh, R.K., Porwal, S.K.: Evaluation of renewable feedstock-derived copolymers of stearyl methacrylate-co-triglyceride as multifunctional green additives in lubricant. Polym. Bull. (2021). https://doi.org/10.1007/ s00289-021-03611-2

41. Singh, N., Agarwal, P., Porwal, J., Porwal, S.K.: Evaluation of multifunctional green copolymer additives-doped waste cooking oil-extracted natural antioxidant in biolubricant formulation. Biomass Conv Bioref (2022). https://doi.org/10.1007/ s13399-022-02348-w
42. ASTM (2004) standard practice for calculating viscosity index from kinematic viscosity at $40^{\circ}$ and $100^{\circ}$. ASTM standard D 2270, Annual book of ASTM standard. ASTM international, West Conshohocken, PA

43. ASTM D97-15 (2015) In: Annual Book of ASTM standards (Eds) Bandini NC, Barkley EI, Brecht LM, Leinweber CM, Mayer VA, Peters KA, Whealen EA, Wilhelm RF, ASTM International, West Conshocken, PA

44. Weimin, Li., Xiaobo, W.: Biolubricant derived from waste cooking oil with oxidation stability and low-temperature properties. J Oleo Sci 64(4), 364-367 (2015)

45. Kuzmić AE, Radošević M, Bogdanić G, Sricá V, Vuković R,: Studies on the influence of long chain acrylic esters polymers with polar monomers as crude oil flow improver additives. Fuel 87, 2943-2950 (2008)

46. Gui, M.M., Lee, K.T., Bhatia, S.: Feasibility of edible oil vs non-edible oil vs waste edible oil as biodiesel feedstock. Energy 33(11), 1646-1653 (2008)

47. Kansedo, J., Lee, K.T., Bhatia, S.: Carberaodollam (sea mango) oil as a promising non-edible feedstock for biodiesel production. Fuel 88(6), 1148-1150 (2009)

48. Porwal J., Porwal S.K., Singh R., Singh K.: Synthetic biofuels and greenhouse gas mitigation. In: Kumar, A., Yau, Y.Y., Ogita, S., Scheibe, R. (eds.) Climate Change, Photosynthesis and Advanced Biofuels. Springer, Singapore (2020). https://doi.org/10.1007/978981-15-5228-1 10

49. Robert, M.: Cost Analysis: The Single Most Important Tool of the Purchasing Profession I Purchasing and Negotiation Training. https://purchasingnegotiationtraining.com. Retrieved Feb 4, 2016 (2011)

Publisher's Note Springer Nature remains neutral with regard to jurisdictional claims in published maps and institutional affiliations. 